\title{
Neighbourhood Regeneration by Facade Redesign: A Visual Experiment on Energy Efficiency and Aesthetics
}

\author{
Francesca Riccardo, Delft University of Technology, Netherlands \\ Clarine van Oel, Delft University of Technology, Netherlands \\ Peter de Jong, Delft University of Technology, Netherlands
}

\begin{abstract}
Energy efficiency and architectural value of post-war residential buildings in Europe is poor. To deal with energy efficiency, decay and livability problems, improvements of building façades seem to be indicated especially when combined with tenants' preferences for architectural aesthetics. But a valid way to assess multiple characteristics of housing façades is lacking. To assess tenant's preferences we used an online visual experiment. In particular, we developed a questionnaire and pilot it with the students of Architecture. All the tested characteristics, i.e. Surface Articulation, Coloring, Sustainable Character, Glazing, Shading and Rent significantly contributed to the valuation of façades. This indicated that such a visual experiment might be sensitive to further investigate tenant's preferences in innovative façade directed renovation approaches as well.
\end{abstract}

Keywords: Social Housing, Neighbourhood Regeneration, Energy Efficiency, Aesthetics

\section{INTRODUCTION}

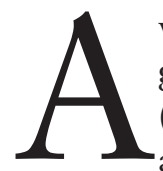

wareness increases that the climate has been changing. The emission of greenhouse gases in the atmosphere from energy use is largely responsible for such a change (Zijlstra, 2009). The European Commission has set ambitious energy targets for 2020 and 2050 which consist of reducing greenhouse gas emissions by $20 \%$, increase the use of renewable resources by $20 \%$ and make a $20 \%$ improvement in energy efficiency (Commission of the European Communities, 2007). In Europe, the building sector is the biggest energy user, accounting for $35.8 \%$ of the total energy consumption. It has been estimated that improving energy efficiency in buildings can lead to a substantial reduction of CO2 emission from the building sector (Knaack, Bilow, Konstantinou, \& Lieverse, 2012). To meet up with European energy efficiency aims, sustainable transformation of the existing housing stock is to be preferred to demolition and renewed construction, because the environmental impact of life cycle extension of existing buildings is lower than of demolition and new construction (Itard, Klunder, \& Visscher, 2006). In addition to ecologic improvements, in fact, transformation may have a direct economic effect by decreasing energy bills, a relevant issue in a period of rising energy costs and impaired purchasing power. Furthermore, social cohesion may be enhanced by improving attractiveness of buildings and solving physical decay, which both affect resident's satisfaction and neighbourhood image. Moreover, appealing transformation can stimulate again the forming of a social network. (van Beckhoven, Bolt, \& van Kempen, 2005; Wassenberg, 2004)

European dwellings built between the 1940s and the 1970s account for $29 \%$ of the total residential stock in Europe (Knaack et al., 2012). Due to the housing shortage after the World

The International Journal of Architectonic, Spatial, and Environmental Design Volume 6, 2013, http://designprinciplesandpractices.com/, ISSN 2325-1662

(C) Common Ground, Francesca Riccardo, Clarine van Oel, Peter de Jong, All Rights Reserved, Permissions: cg-support@commongroundpublishing.com 
War II, numerous social housing blocks were quickly and poorly built, leading to poor energy performance. In several European countries, these neighbourhoods will be regenerated over the coming years and this will offer the chance for sustainable transformation. Measures like roof and facade insulation can cut energy consumption of buildings by half, reducing the overall energy consumption across Europe by $20 \%$ (Esteves, 2007). Poor technical performances of facades are frequently combined with physical deterioration of buildings. Indeed, $80 \%$ of all European building decay is found in the building envelope. The quality of the post war building envelopes will therefore seldom meets the present demands and standards and largely adds to heavy maintenance costs (Verhoef, 2007). In addition to decay, many European including Dutch early post-war large neighbourhoods lack identity and have poor aesthetics (Andeweg \& Koopman, 2007). Typically, these buildings are characterized by plane and grey façades and lack architectural character contributing to a general dissatisfaction of tenants with their housing. This is often associated with vandalism (Melgaard, 2007) and, typically, leads to liveability problems in these neighbourhoods.

Facades are key elements in transformation of buildings. From the previously mentioned ecologic, economic and sustainable relevance of sustainable transformation, it may be concluded that, in fact, facade redesign may particularly add to neighbourhood regeneration by improving energy efficiency, decreasing living costs and enhancing appearances. And, as such, it increases the appeal of the buildings for users and leads to desirable neighbourhoods (Knaack et al., 2012).

\section{Facade Redesign}

First attempts in renovation of social housing date back to the early nineties. Numerous interventions have been implemented in Europe, and especially in the Netherlands, but at that time facade transformation was not yet a big issue. From recent studies, it emerged that frequent architectural solutions were often limited to mural paintings, coloured plastering, enlargement and glazing of small balconies, and redesign of central halls (Brunoro \& Andeweg, 2007). Because of the need to obtain higher energy efficiency levels, more ambitious redesign strategies were only more recently developed. The Facade Research Group at the TU Delft has identified four groups of transformation strategies by envelope redesign. (1) Replace (remove old facade elements and replace with new ones), (2) Wrap it (add a second layer to the façade, i.e. insulation, cladding of balconies or second skin facade), (3) Add on (attach a new structure to the building, e.g. balconies) and (3) Cover it (cover courtyards or atria with new structures, e.g. greenhouses) (Knaack et al., 2012). They all support the improvement of both aesthetic value and energy efficiency of buildings, and as such enhance the livability of neighborhoods. In dealing with liveability problems, one should not only consider physical measures. Social aspects should be addressed as well, and to enhance social cohesion and to make residents feel responsible for their neighbourhood, it might be key to involve their preferences in the process of facade redesign in a more profound way than current practice. There is ample evidence that individual visual preferences for architectural aesthetics share common patterns (Stamps III, 2000).

In his book on psychology and the aesthetics of the built environment, Stamps presents a theory of environmental aesthetics and an overview on several studies showing that aesthetics decisions for facades can be predicted. In evaluating architectural aesthetics, in fact, it is important to distinguish subjective from objective descriptions. Feelings constitute the subjective component of one's judgment, while objects constitute the objective elements. Subjective aesthetics judgments reflect one's personal preferences and are based on feelings of pleasure or displeasure elicited by the form of an object in a representation (e.g. the massiveness of a building). Feelings do not describe the object in itself, but represents the observer's feeling when looking at that particular object. Indeed, to prevent misunderstandings, Stamps pleas for an architectural design practice that adopts more objective and measurable descriptions like 'new 
buildings eight times higher than older buildings will make the block look bad'. After Stamps, the present study deals with aesthetic preferences for facades in which design characteristics stem from geometrical descriptions.

Research indicates that individuals prefer exteriors that express a sense of the past, and have decorated, curved, and grooved surface (T. Herzog, R. \& Shier, 2000; van den Berkhof, 2008). Older buildings are generally preferred as long as they are well-maintained (T. Herzog, R. \& Shier, 2000). Most observers prefer ornate buildings and, in fact, residences with more complex façades are more appreciated. Many studies found that people generally dislike modern or atypical styles and that, independent of location, architectural style has a great effect on their judgment (Stamps III \& Nasar, 1997). There is also evidence of demographic and temporal stability of preferences over countries and time (Stamps III, 1999b), although there might be cultural differences in preferences. In the Netherlands, for instance, the bricks pattern on facades is widely appreciated, whereas building components that are intrusive or otherwise affect the visual landscape are generally disapproved. Also, most of the Dutch home buyers prefer traditional exteriors, whereas only a small minority would opt for experimental or modern architecture (Thissen, 2007).

Renewed façades may improve energy-efficiency of housing, mitigate neighborhood decline, and enhance livability, but all at the expense of high costs. As part of these costs may be compensated by societal savings due to lower emissions of greenhouse gasses and lower costs for maintenance, tenants will be facing higher rents. A previous study, however, showed that residents are willing to pay more for measures that improve the energy efficiency of their homes (van Eck, van Oel, \& Koppels, 2008). Since this research only involves occupant-owners, the important questions are to what extent tenants are willing to pay a higher rent, and whether their willingness depends on selected characteristics of the building facades that have a combined effect on both energy efficiency and the aesthetic value of buildings. The larger aim of the current study is to identify which facade characteristics are preferred by residents to further improve sustainable transformation of social housing in problematic neighborhoods. In terms of practical implications and in line with former studies, results may also serve the design review of renovation projects and the development of regeneration programs based on the adaptation of the built environment.

This part of the study focuses on the Dutch context and post-war middle-rise multifamily blocks which is the most common housing type built between 1945 and 1960 (47\% of the total housing stock in Europe and 30\% in the Netherlands. Boverket, 2005). Reported is the development of a visual experiment to assess tenants' preferences for innovative facade directed renovation along with a pilot study conducted in the Netherlands.

\section{Research Methods}

\section{Discrete Choice Models}

There are several methods to investigate consumers` preferences (also called utility) for a product. In measuring the utility for a product, one can distinguish between revealed preference methods, stated preference methods and non-preference methods (Adamowicz, Louviere, \& Williams, 1994). The revealed preference method is based on the observation of actual made choices of households and individuals, and it assumes that people show their preferences by their actions.

The Stated Preference method is based on information extracted from interviews or choice experiments. An important advantage of the stated preference method over the revealed preference method is that this technique allows for the measurement of peoples opinion to non-economic goods, e.g. comfort, behavior (Hanley, Wright, \& Adamowicz, 1998).

Within the stated preference methods, there is a direct and an indirect method to investigate consumers 'preferences (in the literature sometimes utility is used rather than preferences). The 
direct method is known as the contingent valuation method (CVM). The most important problems of CVM are related to cognitive stress and strategic responses (Fischhoff, Karl-Göran, \& Jeffrey, 2005). People experience difficulties in assigning a value to a product or service. There is also the risk of strategic bias as people might think they can influence the situation. Because of these problems, we employed the indirect or the conjoint analysis method (CAM), more specifically the discrete choice method (DCM).

The DCM is based on efficiency in choice designs using the multinomial logit model (Kuhfeld, 2009). This model assumes that consumers make choices among alternatives that maximize their perceived utility. In the questionnaire, respondents are asked to choose between rendered images of a housing block (see Figures 7, 8 and 9). In each set of two images all the 6 main "design factors" or so called attributes are present. A set of images is referred to as choice set or a discrete choice question, since respondents are asked to choose from each set the one they most liked. Within each image the attributes levels are systematically varied. The way these levels are varied, is optimized. Optimization is strongly recommended with 6 attributes of 3 levels each, as all possible combinations that could be made with these attributes and levels mount up to $(3 * 3 * 3 * 3 * 3 * 3) 729$ images. With this many images there are $((729 * 728) / 2)$ 265365 unique pairs to make. Therefore, we used an algorithm that optimized the number of pairs using an efficient fractional factorial model derived in SAS (Kuhfeld, 2009). We found that the optimal number of discrete choice sets would be 36 , but since we considered this too much for one person to deal with, we made 3 versions of the questionnaire with 12 discrete choice questions each. In the questionnaire, respondents were randomized into one of the 3 versions of the questionnaire. Results were analyzed in SAS 9.2 as well SPSS 17.0 was used in additional analyses. Generally, a threshold of $\mathrm{p}<0.05$ was used in significance testing of the main effects. Interactions were considered significant at a significance level of $\mathrm{p}<0.01$.

\section{Designing the Visual Experiments}

As mentioned before, 36 pairs of images would be sufficient to estimate user preferences for the 6 main attributes (Table 1). The algorithm prescribed for all images what combination of attribute levels should be applied in the visual experiment.

For the visual experiments, visual representations of buildings many techniques can be applied: $3 \mathrm{D}$ and 2D computer-aided design (CAD), photomontage, normal or perspective photographs, sketches, videos (of reality or miniaturized scenes) and virtual reality. In designing the visual experiment we decided to use 3D color simulations of hypothetical buildings. We did so, because photo images were found to perform better than verbal descriptions (Jansen, Boumeester, Coolen, Goetgeluk, \& Molin, 2009). However, a disadvantage of photo images might be that respondents could recognize the buildings and have different associations with it. We solved this problem by using rendered images. Each image showed both normal and perspective view point. It could be argued that there is a difference in evaluations of scenes with different perspective and rendering color. Changing the perspective point, however, does not strongly affect the evaluation outcome (Stamps III, 1999a).

Preferences for facade redesign based on visual experiments will have increased validity if the experiment is replicated in different geographical contexts. Thus, to allow for comparable replications, the simulated buildings were abstracted to avoid recalling for local architectural characteristics (e.g. size and shape). As a basic model, we used a middle-rise multifamily block which is a very common social housing typology in Europe. More specifically, we based our imaging on the hallway-access flat, which is particularly common in the Netherlands (Roeloffzen, Lanting, \& Scholten, 2004) (Figure 1). Our simulations visualized the front of buildings, as it is usually the first side to be perceived approaching the entrance. 

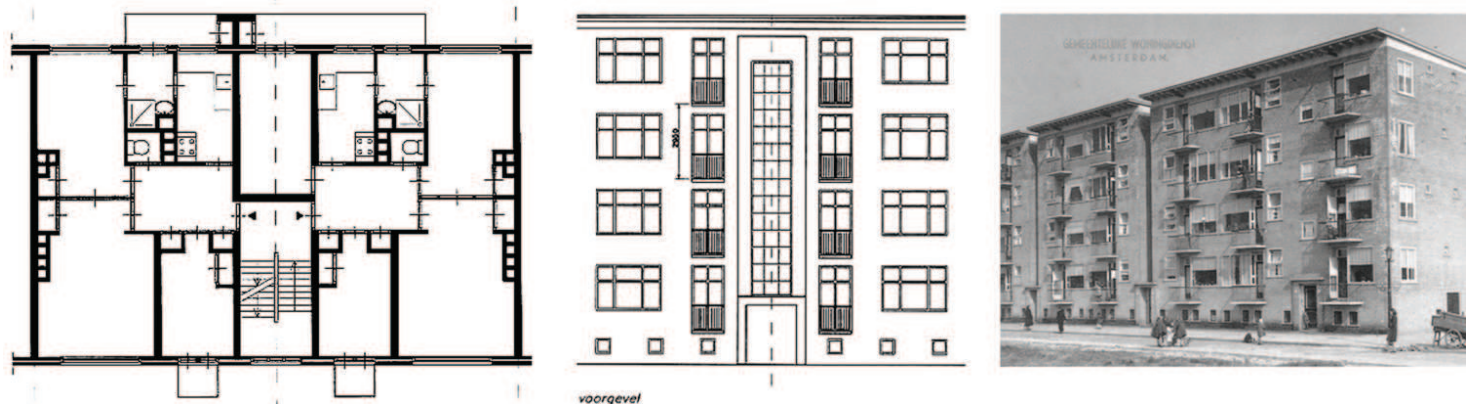

Figure 1: Example of Hallway Access Apartments in Middle-rise Multifamily Blocks in the Netherlands

(Roeloffzen et al., 2004)

\section{Characteristics of Interest in the Visual Experiment}

Envelope redesign implies dealing with numerous attributes having combined effect on aesthetics and energy efficiency of buildings. Several studies showed that physical characteristics of residential façades affect the aesthetic value given by respondents to, for example, form, ornament and architectural style. Aspects frequently investigated are complexity and order, frequency of features, massing, homogeneity, whole to part impression and amount of detail (T. Herzog, R. \& Shier, 2000; Stamps III, 2000; Stamps III \& Nasar, 1997). In this context, facade characteristics with effects on energy efficiency might be related to maximizing compactness, absorbing solar radiation, gaining and maintaining heat, and generating energy and controlling daylight (T. Herzog, Krippner, \& Lang, 2008; Schittich, Lang, \& Krippner, 2006).

From previous work, we learned that six characteristics, or attributes as they are called in Discrete Choice Modeling (DCM), and three levels would be acceptable to be used in visual experiments. To make a selection among the several facade attributes, we first choose those with effects on both aesthetics and energy efficiency. Amount of details, for example, only affects the esthetic value. Secondly, we proceeded with those suitable to describe those projects that, according to the archive of the Dutch National Renovation Prize (2009 and 2007), are considered good practices for renovation in the Netherlands. This applies for example, to building form. This attribute stems from the so-called measure 'optoppen', a Dutch word to describe the addition of dwellings, often differing in shape from the rest of the building, on the top floor of a building (Branders, van Dijk, \& van der Schans, 2000). Along with the 'good practice attributes' we decided to choose for 'innovative facade attributes' as with green walls.

Five of the final attributes are facade characteristics with effects on both aesthetic value and energy efficiency: form, materialization, green walls, windows and sun shadings. This pilot considers the Dutch context; therefore the facade attributes are chosen to fit northern European climates. The sixth attribute, called affordability, concerns the willingness to pay for a rented dwelling. The final attributes are summarized in Table 1 and will be further explained below.

\section{Form}

The form of a facade affects the aesthetic judgment of a building. In particular, the articulation of the outer surface may change the perceived aesthetic value of that building. The complexity in the articulation of a facade surface can be geometrically described applying the convex deficiency. This is defined by the difference (D) in volume between the convex hull $(\mathrm{H})$ of the building and the building itself (B), so that $\mathrm{D}=\mathrm{H}-\mathrm{B}$. The convex hull is the smallest convex shape which would entirely surround a building of a given shape (Stamps III, 2000). For a more generalized design application of convex deficiency we decided to use the convex hull to building ratio $(\mathrm{D}=\mathrm{H} / \mathrm{B})$ rather than the difference in volume. The larger the number of projections 
from a facade (i.e. 'optoppen'), the higher the volumetric convexity. Complexity levels in facade articulation can be obtained by adding and/or subtracting volumes which form may range from straight, inclined and curved to free forms. We know from research that curved facades are preferred but in practice they are not common in social housing. For this reason, in addressing building form by levels of convex deficiency, we considered both curved and straight volumes (Figure 2).

The form of a building is a relevant attribute that affects energy efficiency. Size differences in surface areas influence the heat loss of a building: the smaller the envelope area of a given volume, the lower the heat loss of that building. This relationship can be quantified using the concept of compactness in surface geometry which is calculated by the ratio of the heated-transferring enclosing surface area $(\mathrm{A})$ to the heated volume of the building $(\mathrm{V})$ so that $\mathrm{C}=\mathrm{A} / \mathrm{V}$. For residential buildings to reach the energy requirement equal to $15 \mathrm{kWh} / \mathrm{m}^{2}$ the compactness ratio should be at least 0.2 (T. Herzog et al., 2008). In terms of energy efficiency, low convexity levels of a building volume correspond to high compactness in surface geometry and this leads to lower energy requirements. In addressing building form, we considered the following three levels of convex deficiency according to differences in surface compactness and heat loss (see also Figure 2):

1. convex deficiency 1 by curved volumes and high compactness leading to low heat loss

2. convex deficiency 1.1 by straight volumes and medium compactness leading to medium heat loss

3. convex deficiency 1.2 by inclined volumes and low compactness leading to high loss
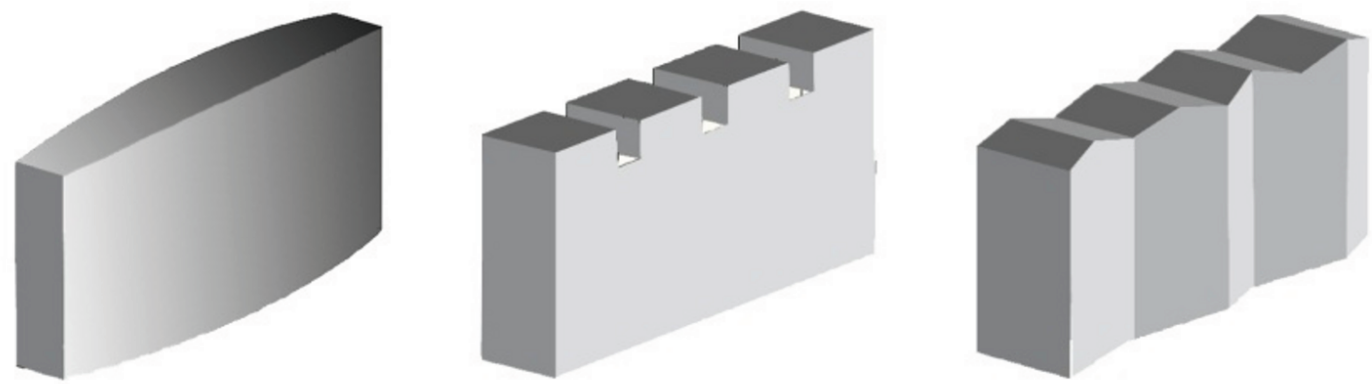

Figure 2: Visual Scheme of Building Form. From Left to Right are Levels I, II and III. Level I Corresponds to Convex Deficiency 1 given by Curved Volumes and no Volume Extensions. This Leads to High Compactness thus Low Heat Loss. On the other Hand, Level II and III Show a Higher Articulation of the Facade. In Level III, for Example, a Higher Convex Deficiency is given by Inclined Volumes on the Vertical Surface and a Fragmented Top Floor. This Results in a Higher Convex Deficiency, Equal to 1.2, which is Less Efficient in Terms of Heat Loss

\section{Materialization}

The surface colouring deals with the so-called materialization of a facade which, in this study, concerns the aesthetic perception of different facade tints corresponding with the types of dwellings in a building (Figure 3). Color is experienced as a fundamental quality in visual perception. Preferences for colors depend on the hue's saturation and brightness. Hue is primarily related to perceived warmth (reds are perceived as warmer, blues and greens as cooler), while brighter colors are considered fresher, lighter, and more cheerful than darker hues (Gifford, 2007). It has been shown that intense colors (independent from hue) and high visual complexity (strong color contrasts) are psychologically stimulating, while subdued colors (grey) have the 
opposite effect. In a comparison of different hues with same intensity saturation, red was found to be more stimulating than blue (Daniels, 2003).

In the Netherlands, when living volumes are added to the building to extend the dwellings or improve housing supply, generally differentiation in facade materials is applied. Therefore, we used three levels of complexity in the materialization of the facade, such that each material corresponds to a type of dwelling (Figure 3). The three types of dwellings are:

1. simplex dwelling (one floor house as in typical middle-rise multifamily blocks)

2. simplex dwelling on top floor and simplex dwelling extended on the outside

3. simplex dwelling extended and simplex dwelling at the bottom
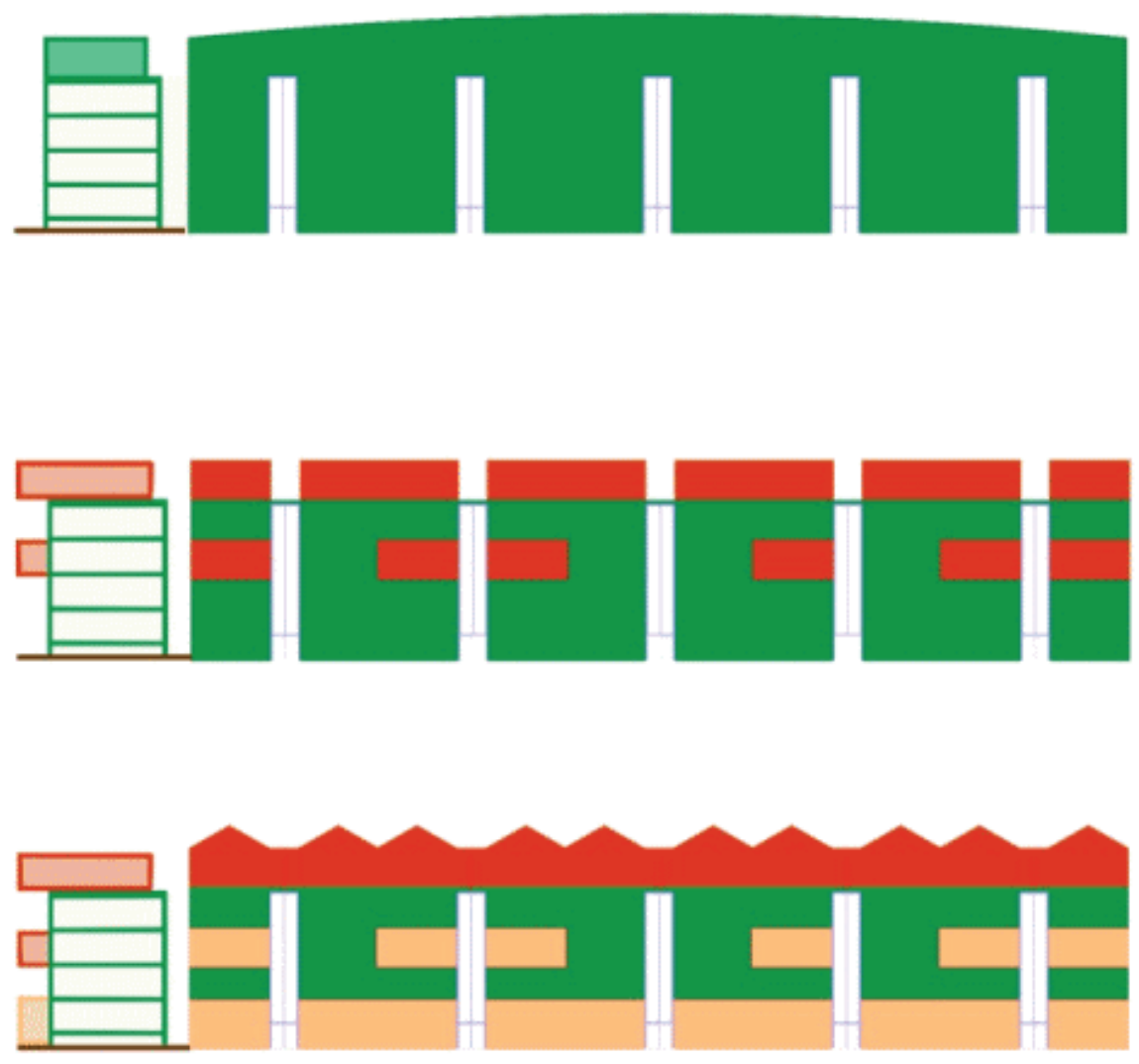

Figure 3: Visual Scheme of Materialization with Front View and Section. From Top to Bottom, the Complexity in the Articulation of the Facade Materials Increases from Level I to III. The same goes for the Articulation in the Types of Dwellings. Level I, for Example, Shows one Material (Thus One Green Color) Applied to the Simplex Dwellings while Level III Exhibits Three Materials, and Three Colors, Attached to the Three Types of Dwellings

Regarding energy efficiency, materialization influences the property of materials to absorb or reflect solar radiation due to their color. Indeed, the color of a surface affects the amount of heat a building absorbs or reflects. Dark colors typically absorb a greater percentage of solar radiation than lighter colored objects. In countries where the cooling season is considerably longer than the heating season, in fact, the use of light-colored envelope materials is more cost effective and energy efficient (Meerow \& Black, 1993). Any material is characterized by an albedo value which expresses the ability of that material to reflect the sun's visible and invisible infrared energy. Light/reflective colored facade materials have higher albedo (close to 1), whereas dark/absorptive materials have low albedo (close to 0 ). To distinguish one color from another the RGB code (Red, Green, Blue) was used. 
The albedo of a material not only depends on color but also on the geometrical characteristics of its surface (e.g. surface marking) and temporal variations (e.g. weathering and wear). In general, envelope materials with high-albedo contribute to high energy efficiency in summer by directly reducing the heat gain by the building's envelope, while low-albedo materials lead to high energy efficiency in winter (Taha, Sailor, \& Akbari, 1992). The energy efficiency of a surface can be optimized by its degree of absorption, i.e. by its coloring. Façades in countries with long heating seasons, like the Netherlands, would be most energy efficient if materials with low to medium albedo are applied. In this study, the facade colors and materials were chosen for their albedo level: very dark greenwood panels 0.15 (RGB 116, 114, 92), dark brown bricks 0.28 (RGB 187, 107, 57), and medium light tan painted concrete panels 0.43 (RGB 238, 171, 121). Those three colors and materials correspond to the three types of dwellings mentioned before (Figure 3).

1. one very dark material with 0.15 albedo to simplex dwellings

2. one very dark material with 0.15 albedo to simplex dwellings, and one dark material with 0.28 albedo to simplex extended and simplex dwellings on top floor

3. one very dark material with 0.15 albedo to simplex dwellings, one dark material with 0.28 albedo to simplex extended and simplex dwellings on top floor, and one medium dark material with 0.43 albedo to simplex dwellings at the bottom

\section{Green Walls}

There are no substantial differences between 'green' and 'sustainable' buildings. According to the World Business Council for Sustainable Development (WBCSD), in fact, the term 'green' is just more prevalent in the U.S. and Asia, while 'sustainable' is commonly used in Europe. Green or sustainable building is 'the practice of creating structures and using processes that are environmentally responsible and resource-efficient throughout a building's life-cycle from siting to design, construction, operation, maintenance, renovation and deconstruction. This practice expands and complements the classical building design concerns of economy, utility, durability, and comfort' (EPA United States Environmental Protection Agency, 2010).

From an architectural perspective, vegetation on a facade is a clear characteristic making a building green. It appears to be aesthetically pleasing and is preferred over traditional coatings. Indeed, aesthetic improvement is one of the design objectives of green walls (vegetated surfaces applied to building facades). Due to their aesthetic potential, green walls are often used to give a building a typical visual character, usually associated with sustainable or environmental friendly appearance. The larger the vegetated surface, the more powerful the visual character of a building and its ecologic appearance (White \& Gatersleben, 2011).

Green walls can be as green as they look. In addition to visual value, in fact, vegetated surfaces imply several environmental benefits for urban areas and for energy efficiency of buildings. Plant-covered walls contribute to the improvement of the thermal performance and sustainability of the built environment (Eumorfopoulou \& Kontoleon, 2009). Moss is among the types of vegetation suitable for green wall. It does not require soil to grow, is affordable and easy to maintain, and is simpler and lighter to construct than traditional green walls. On the other hand, it has troubles growing in direct sunlight thus is more suitable for wet northern climates like the Netherlands. It is estimated that moss tiles have a high $\mathrm{R}$ value, between 15 and 35 (Bitzer, Jo, Lawler, \& Harmon, 2009; verticiel Inc., 2009). The R-value measures the thermal resistance of an insulating material. The higher the R-value, the better the building insulation's effectiveness (Oak Ridge National Laboratory, 2008). Materials with an excellent thermal resistance have a maximum value of R-50 (e.g. vacuum insulated panels), while poor insulation have an $\mathrm{R}$ of about 0.2 (e.g. bricks). 
The visual character of a building depends on the frequency of the facade features shared with the adjacent buildings. In testing the overall character in terms of style and other characteristics, a design feature should be present in $88 \%$ of a building before people would describe the overall character as having that feature (Stamps III, 1999a). Since moss tiles resemble grass in texture and color, and have a good thermal resistance, they are suitable to address preferences for green building. In this experiment, visual preference for green walls is tested by specifying three levels in the partitions (vertical facade areas) covered by moss tiles (Figure 4):

1. $0 \%$ of the facade covered by partitions in moss tiles with thermal resistance $\mathrm{R}-35$

2. $50 \%$ of the facade covered by partitions in moss tiles with thermal resistance $\mathrm{R}-35$

3. $100 \%$ of the facade covered by partitions in moss tiles with thermal resistance R-35
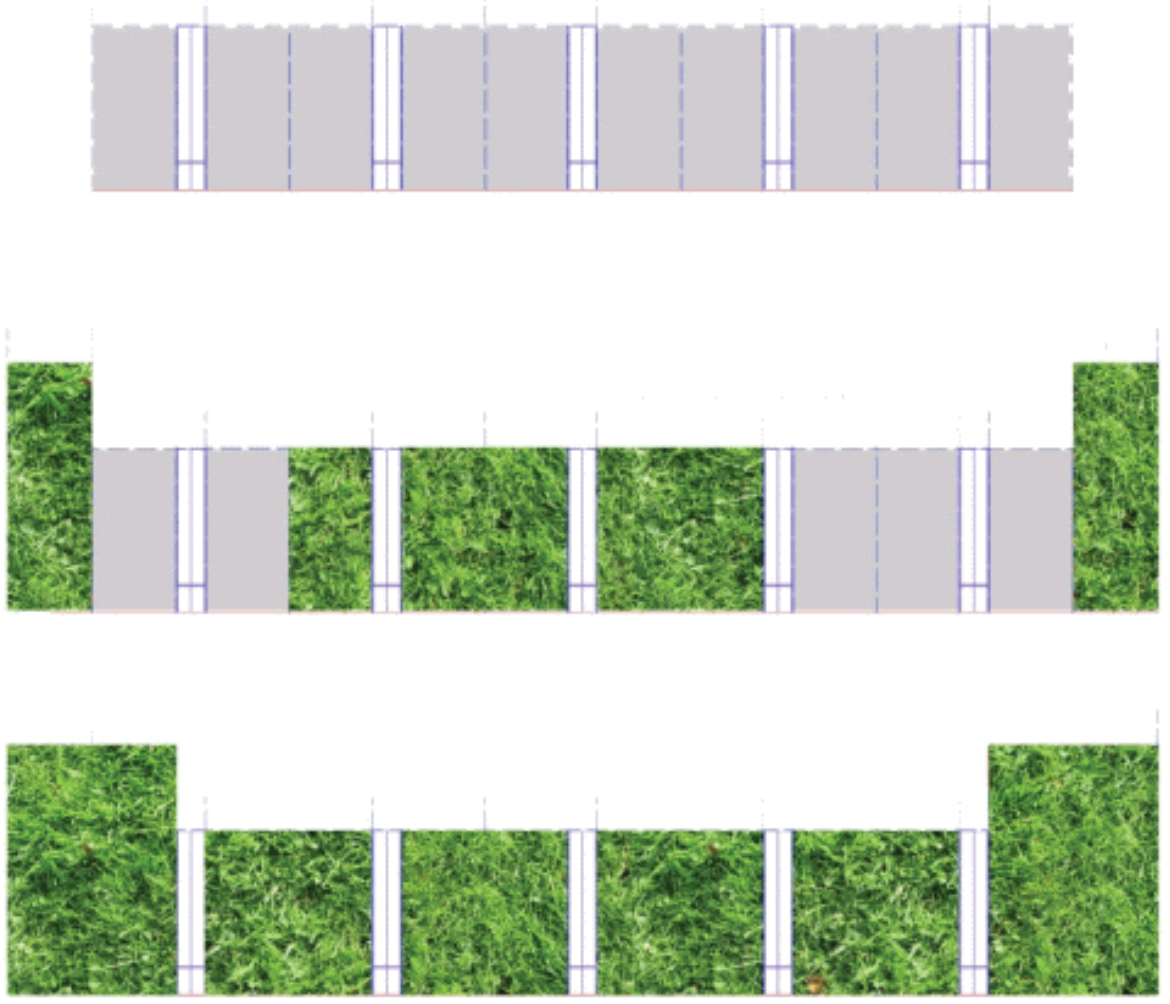

Figure 4: Visual Scheme of Green wall. From Top to Bottom are Levels I, II and III. They show an Increase in the Percentage of the Vertical Facade Areas, or Partitions, Covered by Moss tiles with Good Thermal Resistance (R-35). In Level I this Percentage is $0 \%$ in order to include the Preference for Facades with no Moss at all. From Level II to III the Percentage Increases Going from more than 50\% to $100 \%$

\section{Windows}

The presence of windows in a facade affects the perceived aesthetic value of that building. The architectural design of windows, fenestration, is influenced by factors like shape, size, type and location on the façade. Importantly, the presence of windows in a surface affects the perception of building massing. The more windows, in fact, the less apparent massing. Building fenestration is very important and counts even more than visual area and facade articulation in subjective judgment of massing (Stamps III, 2000). To address the perceived massing, we tested three types of rectangular windows: horizontal windows, vertical windows, and windows covering the whole facade area of a dwelling, here referred to as floor to ceiling windows. To geometrically 
describe each type, we used the height to length ratio $(\mathrm{h} / \mathrm{l})$. Vertical windows, for example, have $\mathrm{a} \mathrm{h} / \mathrm{l}$ ratio of 2.5 , meaning it measures $1.5 \mathrm{~m}$ in height and $0.6 \mathrm{~m}$ in length. Horizontal and floor to ceiling windows are common in Dutch practice. However, vertical windows as arranged in this visual experiment are applied in a repetitive way, creating visual rhythm. Repetition, in fact, may be associated with restless. When elements are spaced they may create a gentle rhythm while large elements may suggest the opposite feeling (Conway \& Roenisch, 2005). By differentiating between horizontal, floor to ceiling and vertical windows we investigate user preferences for both common and a more rarely used type of fenestration, rather than taking existing preferences for granted.

The $\mathrm{h} / \mathrm{l}$ ratio is related to the proportion of glazed area on the facade which is important as it affects the ability of a building to maintain heat. Both proportion of glazing and performances of the glass influence the total primary energy consumption of a building (T. Herzog et al., 2008). As a reference, proportion of glazing is high when the transparent area of a facade is more than $30 \%$. With a higher percentage, thermal performance in summertime needs to be checked.

In this study the proportion of glazing refers to the front facade of each dwelling. The following levels were used in the visual experiment (see also Figure 5):

1. horizontal windows $\mathrm{h} / \mathrm{l}$ ratio by 0.3 with proportion of glazing in the facade $>30 \%$

2. vertical windows with $\mathrm{h} / \mathrm{l}$ ratio by 2.5 with proportion of glazing in the facade $<30 \%$

3. floor to ceiling windows with $\mathrm{h} / \mathrm{l}$ ratio 0.4 with proportion of glazing in the facade $\approx 100 \%$
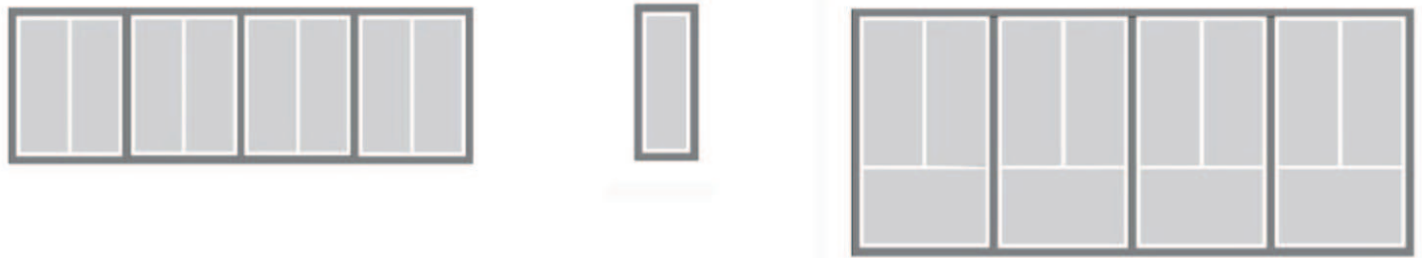

Figure 5: Visual Scheme of Windows. From Left to Right are Visualized level I, II and III. They Correspond to Three Types of Windows Different in Shape and in the Proportion of Glazing in the Facade of a Dwelling. For Example, level I Shows an Horizontal Window which Shape is given by the Height to Length Ratio $(h / l)$ of 0.3 while Level III Visualizes a Floor to Ceiling Window with a Ratio of 0.4. In the First Case, the Window Leads to a Proportion of Glazing of about $30 \%$ and, in the Second, to a Proportion of about $100 \%$

\section{Sun Shadings}

The shading of a building can be provided by sun shading devices attached to the facade itself. Since the devices are combined with the windows in a facade, they may also affect the apparent massing and aesthetics, especially due to the formal features of the manipulator (e.g. color, external or internal location to the façade). Sunshade devices (e.g. louvers, roller shutters, awnings, blinds, shading screens and plantings) can be classified according to material and color. The sun protection of a device depends on three major factors: solar reflectivity, insideoutside location and arrangement of the applied shading. The reduction of solar radiation differs across devices, it increases from venetian blinds to roller shades, outside shading screens, outside metallic blinds, trees, awnings and outside fixed and movable shading devices, respectively (Dubois, 1997).

To address preferences for sun shadings, three types of sun-shading devices were selected based on type and color. Traditional and innovative devices were both visualized in the images. Shading by plants, namely bio-shading, is a relatively new strategy. The term bio-shading describes biological shading devices and comprises a vertical layer of deciduous climbing plant 
canopies that trails on a metal framework. The device is externally mounted to the glazed facade of a building. Actually, in a study of office buildings, it turned out that the solar reduction of leafs went up to $37 \%$ using one layer and even went up to $86 \%$ with five layers. In the same study, it was estimated that the maximum temperature reduction of the interiors in hot summer afternoons was about $5.6^{\circ} \mathrm{C}$ (Ip, Lam, \& Miller, 2010).

Solar shading devices affect the energy efficiency of a building by reducing the incoming solar radiation. The shading coefficient is the ratio of the total solar heat gain from transmitted, absorbed, and reradiated energy by shade and glass combined, to the total solar heat gain from transmission, absorption, and re-radiation by a single un-shaded common window glass (it goes from 1 to 0 , with 1 associated to a common window without shading) (Olgyay, 1963).

The three levels used to address preferences for sunshades are (Figure 6):

1. external retractable venetian blind white-cream colored with shading coefficient 0.15

2. external movable aluminum shading screen with shading coefficient 0.28

3. dense tree performing heavy shade like bio-shading with shading coefficient 0.20
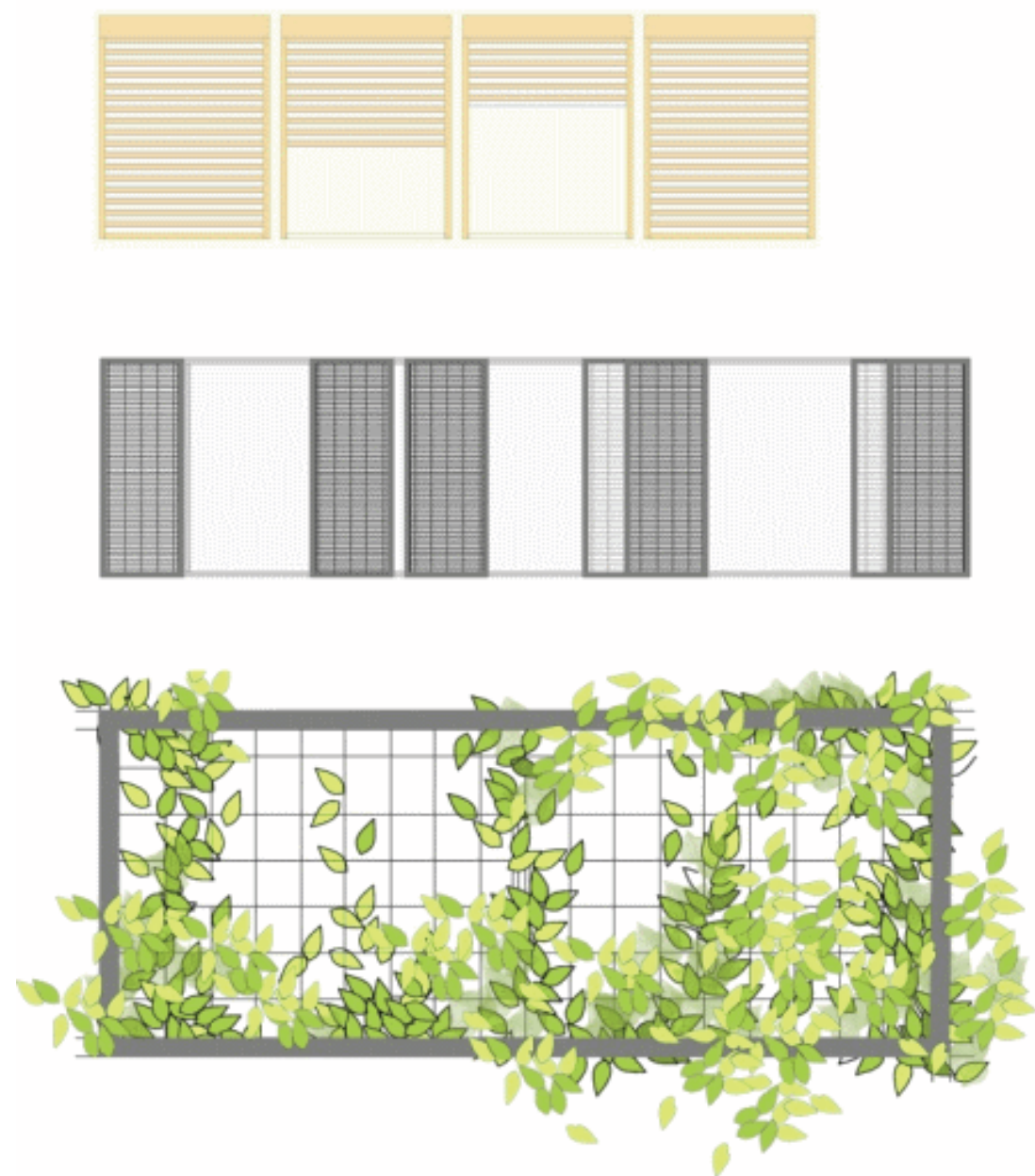

Figure 6: Visual Scheme of Sun Shadings. From Top to Bottom, Level I, II and III Illustrate Three Types of Shading Devices with Increasing Shading Coefficient. Level I Shows an External Retractable Venetian Blind White-cream Colored. This is a Traditional Device with a Shading Coefficient of 0.15. Level II Shows External Movable Aluminum Shading Screen (0.28) while Level III Describes a more Innovative System, Called bioshading. With a Dense Vegetated Surface, it can reach a Coefficient of 0.20 


\section{Affordability}

Social housing in the Netherlands is available for people with annual gross incomes below modal. In 2009/2010 the model income was €32.500 (Centraal Bureau voor de Statistiek, 2011). The Dutch social housing stock is owned and maintained by housing associations. Rents in social housing are determined according to the national Housing Valuation System which assigns credits for dwellings that meet a set of quality criterion (Ministerie van Binnenlandse Zaken en Koninkrijksrelaties, 2011). The maximum number of credits is 150 and the maximum rent for social housing obtaining maximum credits is currently determined at $€ 669.09$. Examples of points associated with housing quality are size of dwelling ( 1 point per $\mathrm{m} 2$ ), additional space ( 0.75 point per $\mathrm{m} 2$ of e.g. storage, garage), technical installations ( 5 point if technical private high performance heating) and facade insulation ( 7 to 8 points). All criteria have a pre-specified maximum of credits that might be assigned. In 2009/2010, a credit corresponded to a maximum of $€ 4.68$. After renewal, rents might increase due to higher maintenance levels up to the maximum rent. For our visual experiment, we decided to use rent levels to assess the willingness of respondents to pay by adding $5 \%$ and $10 \%$ to a baseline rent, all well below the maximum rent for social housing:

1. $€ 550$

2. $€ 575$

3. $€ 600$

Table 1: All the Attributes and the Three Levels Per Attribute

\begin{tabular}{|l|l|}
\hline ATTRIBUTE and LEVEL \\
\hline Form & $\begin{array}{l}\text { I) convex deficiency } 1 \text { by curved volumes with high compactness leading to } \\
\text { low heat loss }\end{array}$ \\
\cline { 2 - 2 } & $\begin{array}{l}\text { II) convex deficiency } 1.1 \text { by straight volumes with medium compactness } \\
\text { leading to medium heat loss }\end{array}$ \\
\cline { 2 - 2 } & $\begin{array}{l}\text { III) convex deficiency } 1.2 \text { by inclined volumes with low compactness leading } \\
\text { to high heat loss }\end{array}$ \\
\hline Materialization & I) one very dark material with 0.15 albedo on simplex dwellings \\
\cline { 2 - 3 } & $\begin{array}{l}\text { II) one very dark material with } 0.15 \text { albedo on simplex dwellings, and one } \\
\text { dark material with } 0.28 \text { albedo on simplex extended and simplex dwellings } \\
\text { on top floor }\end{array}$ \\
\cline { 2 - 3 } & $\begin{array}{l}\text { III) one very dark material with } 0.15 \text { albedo on simplex dwellings, one dark } \\
\text { material with } 0.28 \text { albedo on simplex extended and simplex dwellings on top } \\
\text { floor, and one medium dark material with } 0.43 \text { albedo on simplex dwellings } \\
\text { at the bottom }\end{array}$ \\
\hline Green walls & $\begin{array}{l}\text { I) } 0 \% \text { of the facade covered by partitions in moss tiles with thermal resistance } \\
\text { R-35 }\end{array}$ \\
\hline & $\begin{array}{l}\text { II) }>50 \% \text { of the facade covered by partitions in moss tiles with thermal res- } \\
\text { istance R-35 }\end{array}$ \\
\cline { 2 - 3 } & $\begin{array}{l}\text { III) } 100 \% \text { of the facade covered by partitions in moss tiles with thermal res- } \\
\text { istance R-35 }\end{array}$ \\
\hline
\end{tabular}




\begin{tabular}{|l|l|}
\hline Windows & $\begin{array}{l}\text { I) horizontal windows } \mathrm{h} / \mathrm{l} \text { ratio by } 0.3 \text { with proportion of glazing on the facade } \\
>30 \%\end{array}$ \\
\cline { 2 - 2 } & $\begin{array}{l}\text { II) vertical windows with } \mathrm{h} / \mathrm{l} \text { ratio by } 2.5 \text { with proportion of glazing on the } \\
\text { facade }<30 \%\end{array}$ \\
\cline { 2 - 2 } & $\begin{array}{l}\text { III) floor to ceiling windows with } \mathrm{h} / \mathrm{l} \text { ratio } 0.4 \text { with proportion of glazing on } \\
\text { the facade } \approx 100 \%\end{array}$ \\
\hline Sun shadings & $\begin{array}{l}\text { I) external retractable venetian blind white-cream colored with shading coef- } \\
\text { ficient } 0.15\end{array}$ \\
\cline { 2 - 2 } & II) external movable aluminum shading screen with shading coefficient 0.28 \\
\hline & $\begin{array}{l}\text { III) dense tree performing heavy shade like bio-shading with shading coefficient } \\
0.20\end{array}$ \\
\hline Affordability & I) $€ 550$ \\
\cline { 2 - 3 } & II) $€ 575$ \\
\cline { 2 - 2 } & III) $€ 600$ \\
\hline
\end{tabular}
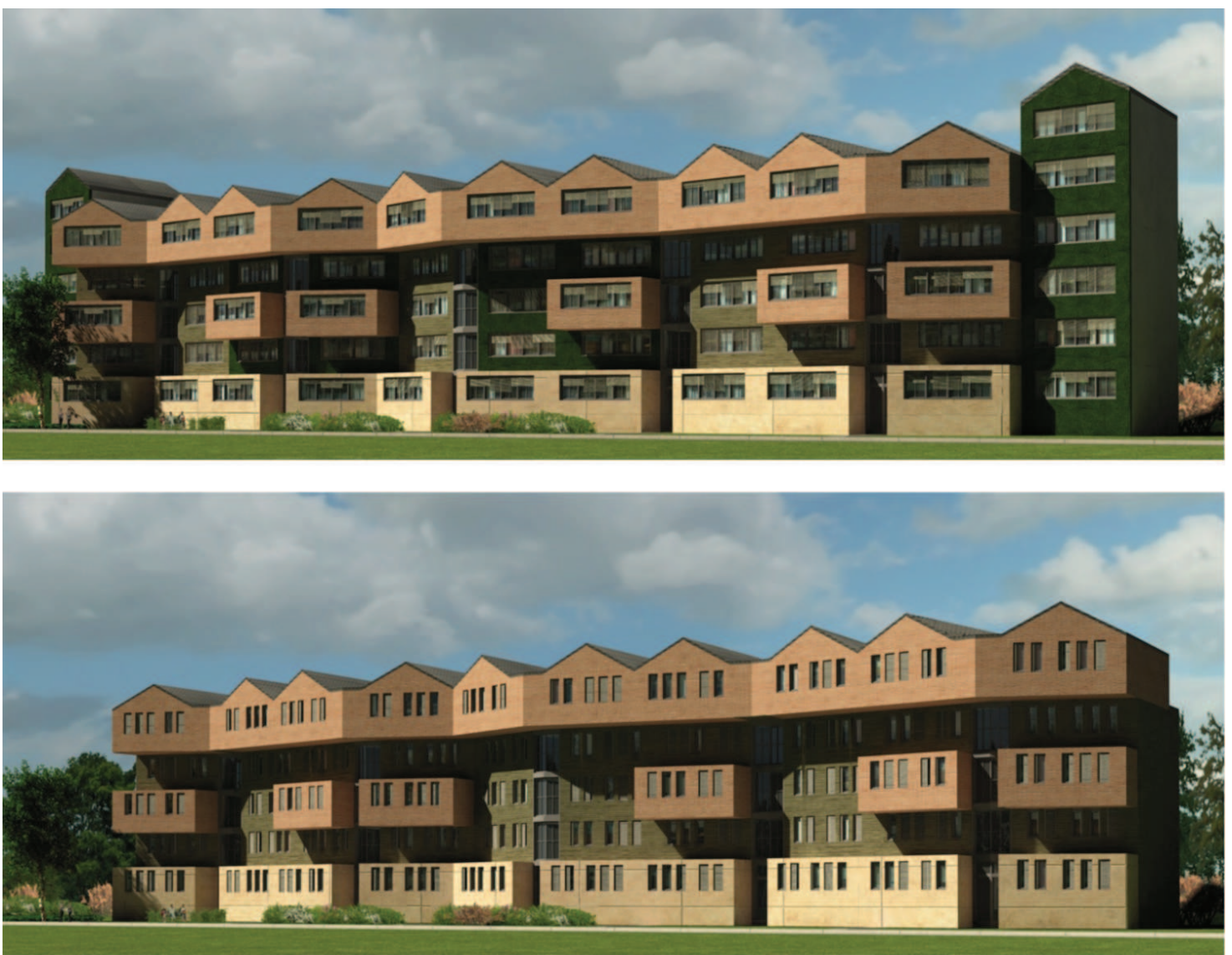

Figure 7: Combinations from set 23. Top Picture: Form Level III, Materialization Level III, Green Walls Level II, Windows I, Sun Shadings Level I, and Affordability Level II. Bottom Picture: Form Level III, Materialization Level III, Green Walls Level I, Windows Level II, Sun Shadings level II, and Affordability Level III 


\section{The Pilot Questionnaire}

To investigate whether or not the visual experiments were properly designed, that is whether or not the attributes were recognized by respondents and eventually influenced respondents' choice behavior, a pilot questionnaire was designed. The questionnaire consisted of 3 parts. The first part collected general information on the student, then students did 12 discrete choice questions constituting the visual experiment, and then there were some closing questions. As mentioned before, there were three versions of the questionnaire available and students were randomly assigned into one of these versions. Figure 7, 8 and 9 show the images presented to the respondents in the visual experiment, and illustrate how different combinations of attribute levels look like.

The images were rendered using the software $3 \mathrm{~d}$ s max in combination with Maya. Since 72 combinations were needed for an efficient (statistical) design, obtaining 3D images with both front and corner view required the rendering of 144 images. Due to software limitations, each of the building objects needed for visualization was designed as an independent (external reference) file. The files were then mounted on master scenes according to the required combination of attributes and then exported in Maya for the rendering.
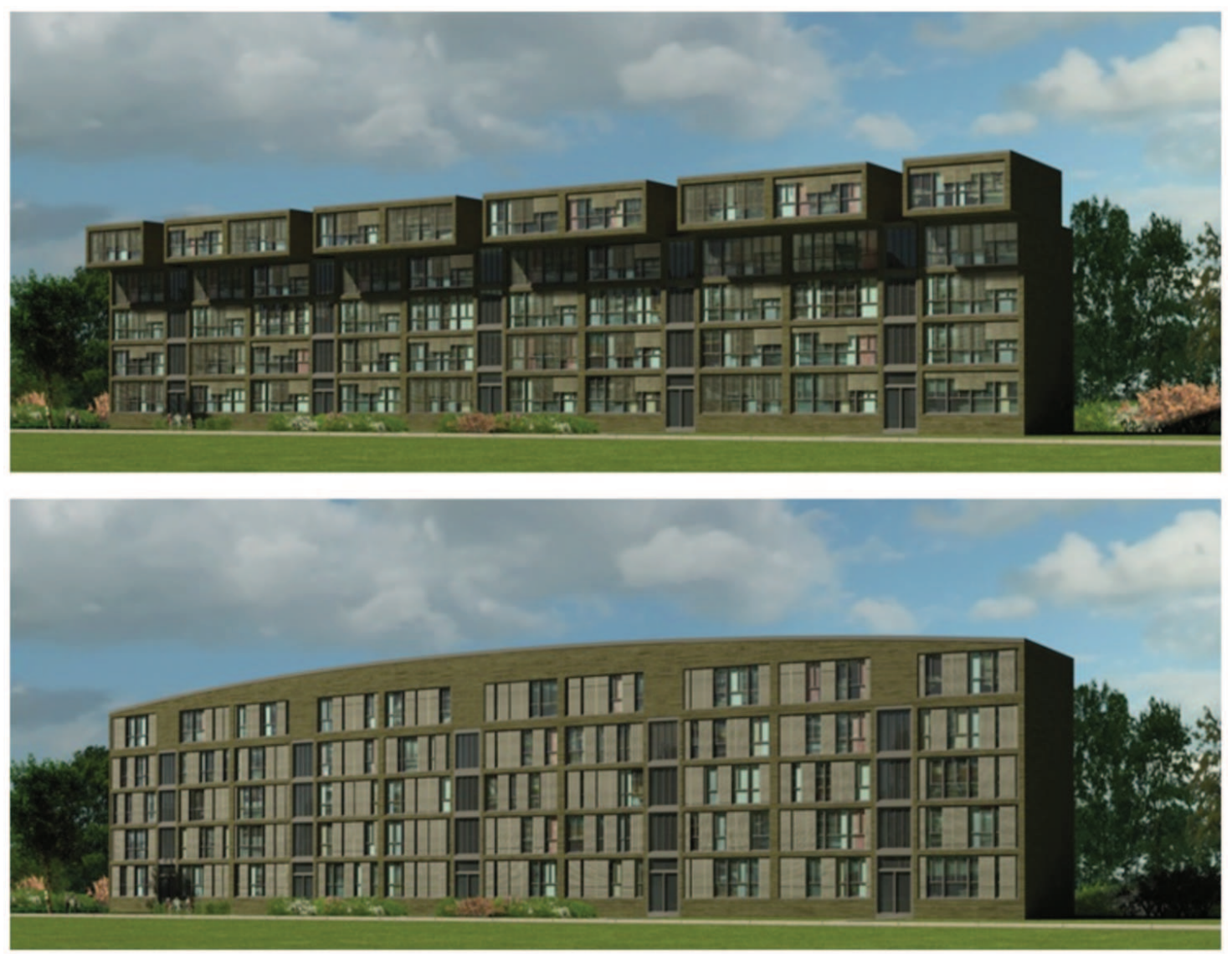

Figure 8: Combinations from set 35. Top Picture: Form Level II, Materialization Level I, Green Walls Level I, Windows Level III, Sun Shadings Level I, and Affordability Level III. Bottom Picture: Form Level I, Materialization Level I, Green Walls Level I, Windows Level III, Sun Shadings Level II, and Affordability Level III 


\section{Respondents}

To address the validity of the questionnaire we piloted it at the Faculty of Architecture of Delft University of Technology. A total of 438 students ( 244 men, 189 women, 5 unknown) from the first year bachelor could earn credits for their exam by filling out the online questionnaire. The average age of the students was $20.1 \mathrm{yrs}$ (sd: $2.7 \mathrm{yrs}$ ). Most (433) of the students were born in The Netherlands, few (20) were born in another European country, whereas another 36 students were born outside Europe. Most (358) of the students only studied Architecture; 19 students studied some other study at a University of Technology; 26 did a second study at a general University. There were 30 students who had attended a study at a Bachelor college before starting their study of Architecture at Delft University of Technology.
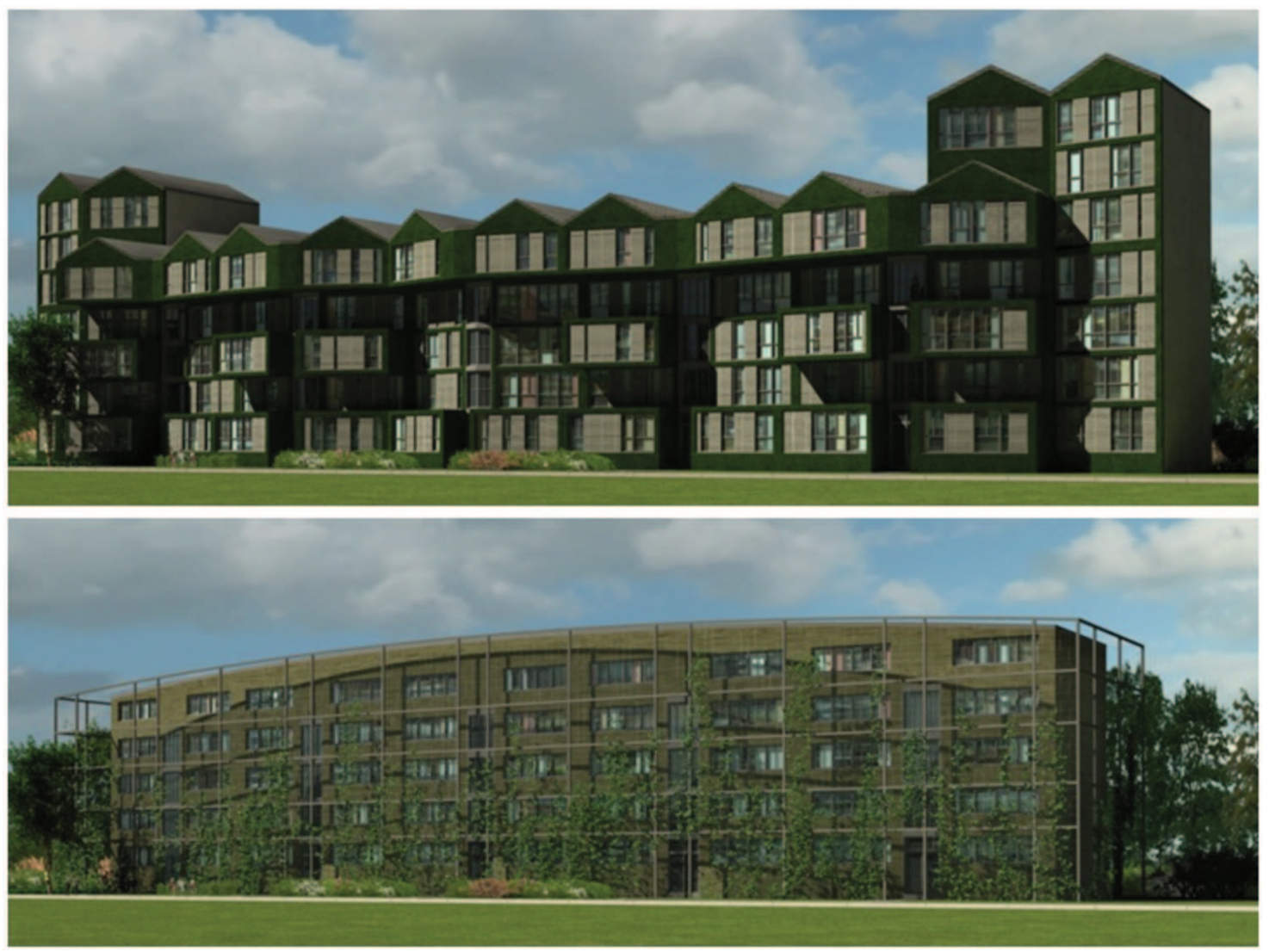

Figure 9: Combinations from Set 31. Top Picture: Form Level III, Materialization Level III, Green Walls Level III, Windows III, Sun Shadings Level II, and Affordability Level II. Bottom Picture: Form Level I, Materialization Level I, Green Walls Level I, Windows Level I, Sun Shadings Level III, and Affordability Level I

\section{Results}

The choice patterns of all students were analyzed using the multinomial logit model. This model assumes that the students make choices among alternatives that maximize their perceived utility. In Table 2, for all 6 attributes that were systematically varied in the images, the importance of the selected attributes in choosing the building that was most attractive to them, is shown as the estimated utility of all six factors. The higher the estimated absolute utility, the more weight the characteristic has in deciding about attractiveness. For example, Windows shows the highest utility $(0.23)$ meaning it is the most important attribute in aesthetic decisions. Since we did the pilot to see whether all characteristics made sense, an important conclusion 
from the results in Table 2 , is that all the characteristics of interests significantly affected the students' choice for one of the facades and are therefore relevant to perceived aesthetic value of the facades. This can be concluded from the p-value which expresses the significance level of an attribute in the choice for the most preferred facade. All the characteristics of interest were significantly $(\mathrm{p}<0.05)$ affecting the decision for the preferred facade leading us to the conclusions that at least all characteristics were operationalized in a valid way. Would one of the characteristics of interest showed no significant relationship with choosing the most attractive facade, then this might be so because the characteristic does not affect students' choice behavior, or it could be that the way such a design characteristic was visualized (operationalized) in the images was not done in a consistent way.

Table 2: Aesthetic Appreciation for Facade Attributes. Utility Expresses the Weight of an Attribute in the Decision for the most Attractive Building. P-value Indicates how Significantly an Attribute Affect the Choice for a Facade

\begin{tabular}{|l|c|c|c|}
\hline ATTRIBUTE & UTILITY & $\mathbf{X}^{2}$ & P-VALUE \\
\hline Form & 0.06 & 5.4 & 0.02 \\
\hline Materialization & -0.05 & 3.71 & 0.05 \\
\hline Green walls & 0.13 & 29.73 & $<0.01$ \\
\hline Windows & 0.23 & 88.8 & $<0.01$ \\
\hline Sun shadings & 0.18 & 52.27 & $<0.01$ \\
\hline Affordability & -0.17 & 51.87 & $<0.01$ \\
\hline
\end{tabular}

For further interpretation of the results of Table 2, one needs to know what the reference level for all characteristics is. Students always had to choose the most preferred from a pair of images, so the kind of conclusion would be always that the students preferred an attribute level relative to another level. In the analyses, the preference of one level over the reference level is estimated and therefore the value of the reference level is set to zero. Both Form and Materialization of the facades were less important compared to Green walls, Windows, Sun shading and Affordability, as the utility estimates are in the lower ranges (Table 2, Table 3). A negative value means that the reference level is more preferred than that particular level, thus a convex, curved facade with high compactness (Form I) is significantly less preferred than the higher convex deficiency building (Form III). Thus, regarding Form, the top picture in Figure 9 is preferred to the bottom picture. The difference with the other Form level (Form II, see top picture in Figure 8) and the higher convex deficiency building is not significant. In practice, this suggests that despite of being more energy efficient, less articulated Building form are not appealing to people.

Students also preferred the very dark coloured facades (as in the top picture of Figure 8) more than the blocks that had multiple colouring due to the materialisation used (as in the top picture of Figure 9) and preferred the use of moss tiles (the complete coverage with moss tiles as in the top picture in Figure 9 was preferred over absence of moss tiles as in the other picture in Figure 9). 
Table 3: Students' Preferences for the Visualized Levels of each Characteristic of Interest as Compared to the Reference Level of each Characteristic. The Hazard Ratio (HR) Provides Information about the Frequency the Level of Interest is Preferred over the Reference Level. If the HR is 1.0 then both Levels are Equal, a HR $<1$ Favours the Reference Level, if HR $>1.0$ the other Level is Preferred over the Reference Level

\begin{tabular}{|c|c|c|c|c|c|}
\hline \multicolumn{2}{|c|}{ ATTRIBUTE and LEVEL } & UTILITY & HR & $\mathrm{X}^{2}$ & P VALUE \\
\hline \multirow[t]{3}{*}{ Form } & $\begin{array}{l}\text { I) convex deficiency } 1 \text { by } \\
\text { curved volumes with high } \\
\text { compactness leading to low } \\
\text { heat loss }\end{array}$ & -0.12 & 0.88 & 6.36 & 0.01 \\
\hline & $\begin{array}{l}\text { II) convex deficiency } 1.1 \text { by } \\
\text { straight volumes with medi- } \\
\text { um compactness leading to } \\
\text { medium heat loss }\end{array}$ & 0.07 & 1.08 & 2.10 & 0.15 \\
\hline & $\begin{array}{l}\text { III) convex deficiency } 1.2 \text { by } \\
\text { inclined volumes with low } \\
\text { compactness leading to high } \\
\text { heat loss }\end{array}$ & reference & & & \\
\hline \multirow[t]{3}{*}{ Materialization } & $\begin{array}{l}\text { I) one very dark material } \\
\text { with } 0.15 \text { albedo on simplex } \\
\text { dwellings }\end{array}$ & 0.10 & 1.11 & 3.83 & 0.05 \\
\hline & $\begin{array}{l}\text { II) one very dark material } \\
\text { with } 0.15 \text { albedo on simplex } \\
\text { dwellings, and one dark ma- } \\
\text { terial with } 0.28 \text { albedo on } \\
\text { simplex extended and sim- } \\
\text { plex dwellings on top floor }\end{array}$ & -0.01 & 0.99 & 2.10 & 0.15 \\
\hline & $\begin{array}{l}\text { III) one very dark material } \\
\text { with } 0.15 \text { albedo on simplex } \\
\text { dwellings, one dark material } \\
\text { with } 0.28 \text { albedo on simplex } \\
\text { extended and simplex dwell- } \\
\text { ings on top floor, and one } \\
\text { medium dark material with } \\
0.43 \text { albedo on simplex } \\
\text { dwellings at the bottom }\end{array}$ & reference & & & \\
\hline \multirow[t]{2}{*}{ Green walls } & $\begin{array}{l}\text { I) } 0 \% \text { of the facade covered } \\
\text { by partitions in moss tiles } \\
\text { with thermal resistance R-35 }\end{array}$ & -0.28 & 0.75 & 29.84 & $\mathrm{P}<0.01$ \\
\hline & $\begin{array}{l}\text { II) }>50 \% \text { of the facade } \\
\text { covered by partitions in moss } \\
\text { tiles with thermal resistance } \\
\text { R-35 }\end{array}$ & 0.04 & 1.04 & 0.70 & 0.40 \\
\hline
\end{tabular}




\begin{tabular}{|c|c|c|c|c|c|}
\hline & $\begin{array}{l}\text { III) } 100 \% \text { of the facade } \\
\text { covered by partitions in moss } \\
\text { tiles with thermal resistance } \\
\text { R-35 }\end{array}$ & reference & & & \\
\hline \multirow[t]{3}{*}{ Windows } & $\begin{array}{l}\text { I) horizontal windows } \mathrm{h} / \mathrm{l} \mathrm{ra}- \\
\text { tio by } 0.3 \text { with proportion of } \\
\text { glazing on the facade }>30 \%\end{array}$ & -0.50 & 0.61 & 94.58 & $\mathrm{P}<0.01$ \\
\hline & $\begin{array}{l}\text { II) vertical windows with } \mathrm{h} / \mathrm{l} \\
\text { ratio by } 2.5 \text { with proportion } \\
\text { of glazing on the facade } \\
<30 \%\end{array}$ & -1.01 & 0.38 & 349.93 & $\mathrm{P}<0.01$ \\
\hline & $\begin{array}{l}\text { III) floor to ceiling windows } \\
\text { with } h / 1 \text { ratio } 0.4 \text { with pro- } \\
\text { portion of glazing on the } \\
\text { facade } \approx 100 \%\end{array}$ & reference & & & \\
\hline \multirow[t]{3}{*}{ Sun shadings } & $\begin{array}{l}\text { I) external retractable vene- } \\
\text { tian blind white-cream } \\
\text { colored with shading coeffi- } \\
\text { cient } 0.15\end{array}$ & -0.37 & 0.69 & 52.10 & $\mathrm{P}<0.01$ \\
\hline & $\begin{array}{l}\text { II) external movable alumin- } \\
\text { um shading screen with } \\
\text { shading coefficient } 0.28\end{array}$ & -0.42 & 0.65 & 70.42 & $\mathrm{P}<0.01$ \\
\hline & $\begin{array}{l}\text { III) dense tree performing } \\
\text { heavy shade like bio-shading } \\
\text { with shading coefficient } 0.20\end{array}$ & reference & & & \\
\hline \multirow[t]{3}{*}{ Affordability } & I) $€ 550$ & 0.40 & 1.50 & 60.29 & $\mathrm{P}<0.01$ \\
\hline & II) $€ 575$ & -0.05 & 0.95 & 0.92 & 0.34 \\
\hline & III) $€ 600$ & reference & & & \\
\hline
\end{tabular}

Furthermore, as expected, students preferred floor to ceiling windows (top picture in Figure 9) over horizontal (top picture in Figure 7) and vertical fenestration (bottom picture in Figure 7). As mentioned before, horizontal and floor to ceiling windows are common in Dutch practice. The vertical windows were clearly negatively valued. The Hazard Ratio in Table 3 shows that floor to ceiling windows are about $2.5(1 / 0.38)$ times more frequently preferred to vertical windows.

Sun shading was also found to have a rather large impact on students' preferences for the appearance of the facades. They favoured bio-shading as in the bottom picture of Figure 9, much more than the two other types of shading (see for Venetian blinds top picture of Figure 8, and for aluminium shading screens the bottom picture in Figure 8). Finally, affordability represented the rent levels visible on all pictures. As might be expected, students most strongly valued the lowest price level (level 1), but pricing did not outweigh the other characteristics. 


\section{Conclusions}

We described the results of a pilot study of an online visual experiment developed to address, in the near future, to what extent tenants are willing to pay higher rent for housing with redesigned facades, and whether their willingness to pay higher rent depends on selected characteristics of facades that have a combined effect on the energy efficiency and aesthetics value of buildings. The pilot was conducted with students in Architecture. It emerged that all the chosen facade characteristics, i.e. Form, Materialization, Green walls, Windows, Shading and Affordability significantly contributed to the students' valuation of facades.

As from past research, architects can not predict aesthetic preferences of laypersons (Akalin, Yildirim, Wilson, \& Kilicoglu, 2009; Gifford, Hine, Muller-Clemn, \& Shaw, 2002). To help designers producing aesthetically pleasing and energy efficient facade directed transformations of social housing from the post war period, our results tentatively suggest that the priority in design decisions should be given to Windows, Sun shading devices and Green walls. Form and Materialization were found less important in aesthetic judgment.

More in particular, it emerged that curved facades were less appreciated, therefore the addition of straight or inclined volumes at the bottom, the vertical surface and the top floor of a building might increase the attractiveness of a block (convex deficiency between 1.1 and 1.2). Despite of being more effective in terms of energy efficiency, in fact, less articulated and curved building forms are not appealing to people and should be avoided. This confirms and enriches results from previous studies showing a U-shaped relationship between complexity and preference (Akalin et al., 2009; Berlyne, 1974; Imamoglu, 2000). That is, when compared to minimum and maximum levels of complexity, the intermediate levels of complexity are most preferred. Maximum levels of visual information are difficult to be decoded as people find it difficult to enjoy scenes where the wholeness is overwhelmed by particularity. On the other hand, oversimplified patterns do not give much pleasure (Chan, 1998). This may explain the lack of appealing for the typical plain facades of the post war social housing blocks.

We expected similar results in the aesthetic evaluation of facade materials but, quite surprisingly, one single material appeared to be preferred to multiple materials or colours. This suggests that for attractive renovation it would be better to choose one very dark material (e.g. greenwood panels) rather than a more complex combination of materials and colours. In terms of energy efficiency, this choice well applies to blocks in northern climates in that the preferred material has a low albedo value (0.1). Green walls are often used for embellishment of buildings and actually students appreciated $100 \%$ of the facade in moss tiles. This result is in line with conclusions from other researchers showing that vegetated facades are more preferred, and were considered more beautiful and aesthetically pleasing compared to those without vegetation (White \& Gatersleben, 2011). If the external layer of a building is not profoundly deteriorated, the tiles can be applied on the outside adding to the thermal resistance of the facade (R-35 for moss tiles). As expected and in line with the tradition in the Netherlands, in a profound renovation it would be more aesthetically pleasing to use floor to ceiling windows, with a height to length ratio by 0.4 , rather than horizontal or vertical windows. But larger glazing implies possible overheating in summertime. This could be prevented adding sun shading devices. For an attractive and energy efficient design of renovation, it would be preferable to adopt bioshading. On the other hand, it should be considered that such a system involves additional costs for the growing and the maintenance of the vegetation.

We used a student sample to pilot the questionnaire and to investigate whether the way the attributes were visualized in the visual experiments affected the choice for the most preferred facade. The results need to be replicated in a less biased sample from the general population. Pricing did not outweigh other characteristics, and this might be true only for this particular sample of students. Also, the clear preference for bio-shading or certain other design character- 
istics might stem from the popularity of features within a population of students all studying Architecture.

In conclusion, this study indicated that the 3D rendered images adopted might be sufficiently sensitive for further analysis. In particular, such imaging seems to be suitable to investigate further tenant's preferences in innovative facade directed transformation of existing post-war housing. Such a renovation approach will lead to an improvement of energy efficiency and cope with livability issues, both relevant in declining neighborhoods standing for regeneration. 


\section{REFERENCES}

Adamowicz, W., Louviere, J., \& Williams, M. (1994). Combining Revealed and Stated Preference Methods for Valuing Environmental Amenities. Journal of Environmental Economics and Management, 26(3), 271-292.

Akalin, A., Yildirim, K., Wilson, C., \& Kilicoglu, O. (2009). Architecture and engineering students' evaluations of house façades: Preference, complexity and impressiveness. Journal of Environmental Psychology(29), 8.

Andeweg, M., T., \& Koopman, F., W., A. (2007). State of the Art: The Netherlands. In L. Bragança, C. Wetzel, V. Buhagiar \& L. Verhoef, G., W. (Eds.), COST C16. Improving the Quality of Existing Urban Building Envelopes. State of the Art (Vol. 2, pp. 95-109). Delft: IOS Press BV.

Berlyne, D., E. (1974). Studies in the new experimental aesthetics: Steps toward an objective psychology of aesthetic appreciation. New York Wiley.

Bitzer, H., Jo, M., Lawler, B., \& Harmon, M. (2009). Critical Moss. Paper presented at the SOLAR 2009. $38^{\text {th }}$ ASES National Solar Conference 2009.

Boverket. (2005). Housing Statistics in the European Union 2004. Karlskrona, Sweden: National Board of Housing Building and Planning Sweden and Ministry for Regional Development of the Czech Republic.

Branders, E., van Dijk, R., \& van der Schans, E. (2000). ReUrbA. Transformation principles. Brunoro, S., \& Andeweg, M., T. (2007). Conclusions. In L. Bragança, C. Wetzel, V. Buhagiar \& L. G. W. Verhoef (Eds.), COST C16. Improving the Quality of Existing Urban Building Envelopes. State of the Art (Vol. 2, pp. 241-255). Delft: IOS Press BV.

Centraal Bureau voor de Statistiek. (2011). Statline. Retrieved november 17, from www.cbs.nl

Chan, L., K. (1998). Less is more or a bore? Detail and formal complexity in architecture. Hong Kong Papers in Design and Development(1), 9.

Commission of the European Communities. (2007). Communication from the Commission to the Council, the European Parliament, the European Economic and Social Committee and the Committee of the Regions-A European strategic energy technology plan (SETplan)-'Towards a low carbon future'. Retrieved December, 22, 2007. from http://eurlex.europa.eu.

Conway, H., \& Roenisch, R. (2005). The exterior. In Understanding Architecture: An Introduction to Architecture and Architectural History (Second Edition ed.). New York: Routledge.

Daniels, K. (2003). Advanced Building Systems. A Technical Guide for Architects and Engineers (1 ed.). Basel: Birkhäuser

Dubois, M., C. (1997). Solar Shading and Building Energy Use. A Literature Review. Part 1. Report TABK (pp. 1-117). Lund, Sweden: Lund Institute of Technology, Department of Building Science.

EPA United States Environmental Protection Agency. (2010). Green Building. Basic Information. Retrieved April 10, 2012, from www.epa.gov

Esteves, L. (2007). Europe's building requirements are falling behind the times. EURIMA Press Release Retrieved December 18, 2007, from www.eurima.org

Eumorfopoulou, E., A., \& Kontoleon, K., J. (2009). Experimental approach to the contribution of plant-covered walls to the thermal behavior of building envelopes. Building and Environment, 5(44), 1024-1038.

Fischhoff, B., Karl-Göran, M., \& Jeffrey, R. V. (2005). Chapter 18 Cognitive Processes in Stated Preference Methods. In Handbook of Environmental Economics (Vol. Volume 2, pp. 937-968): Elsevier.

Gifford, R. (2007). Environmental psychology. Principles and practice $\left(4^{\text {th }}\right.$ ed.). Colville, WA: Optimal Books. 
Gifford, R., Hine, D. W., Muller-Clemn, W., \& Shaw, K. T. (2002). Why architects and laypersons judge buildings differently: cognitive properties and physical bases. Journal of Architectural and Planning Research, 19, 17.

Hanley, N., Wright, R., \& Adamowicz, V. (1998). Using choice experiments to value the environment. Environmental and Resource Economics, 11(3), 413-428.

Herzog, T., Krippner, R., \& Lang, W. (2008). Facade construction manual (Detail ed.). Munich: Birkhäuser

Herzog, T., R., \& Shier, R., L. (2000). Complexity, Age, and Building Preference. Environment and Behavior, 32(4), 557-575.

Imamoglu, Ç. (2000). Complexity, preference and familiarity: architecture and nonarchitecture Turkish students' assessments of traditional and modern house façades. Journal of Environmental Psychology(20), 12.

Ip, K., Lam, M., \& Miller, A. (2010). Shading performance of a vertical deciduous climbing plant canopy. Building and Environment, 45(1), 81-88.

Itard, L., Klunder, G., \& Visscher, H. (2006). Environmental impacts of renovation: The Dutch housing stock compared with new construction'. In V. Gruis, H. Visscher \& R. Kleinhans (Eds.), Sustainable neighbourhood transformations. Delft Delft University Press.

Jansen, S., Boumeester, H., Coolen, H., Goetgeluk, R., \& Molin, E. (2009). The impact of including images in a conjoint measurement task: evidence from two small-scale studies. Journal of Housing and the Built Environment, 24(3), 271-297.

Knaack, U., Bilow, M., Konstantinou, T., \& Lieverse, B. (2012). imagine 06 - REIMAGINING THE ENVELOPE. Rotterdam: 010 Publisher

Kuhfeld, W., F. (2009). Marketing Research Methods in SAS. Experimental Design, Choice, Conjoint, and Graphical Techniques. Cary, NC, USA: SAS Institute Inc.

Meerow, A., W., \& Black, R., J. (1993). Enviroscaping to Conserve Energy: A Guide to Microclimate Modification. Circular EES-43 (IFAS ed., pp. 1-10). Gainesville, Florida University of Florida.

Melgaard, E. (2007). General Conclusions. In L. Bragança, C. Wetzel, V. Buhagiar \& L. G. W. Verhoef (Eds.), COST C16 Improving the Quality of Existing Urban Building Envelopes. Needs (Vol. 3, pp. 149-151). Delft: IOS Press BV.

Ministerie van Binnenlandse Zaken en Koninkrijksrelaties. (2011). Nieuw puntensysteem woningwaarderingstelsel. Retrieved October, 5, 2009, from www.rijksoverheid.nl

Oak Ridge National Laboratory. (2008). Insulation Fact Sheet (pp. 1-33). Oak Ridge, Tennessee: U.S. Department of Energy.

Olgyay, V. (1963). Design with climate: bioclimatic approach to architectural regionalism. Princeton, NJ: Princeton University Press.

Roeloffzen, J., F., T., Lanting, R., \& Scholten, N., P., M. (2004). High-Rise Housing In The Netherlands: Past, Present And Sustainability Outlook. Delft, The Netherlands: TNO Bouw.

Schittich, C., Lang, W., \& Krippner, R. (2006). Building skins. Munich: Birkhäuser Verlag AG.

Stamps III, A., E. (1999a). Defining block character. Environmental and Planning B: Planning and Design, 26(5), 685-710.

Stamps III, A., E. (1999b). Physical Determines of preferences for residential facades Environment and Behavior, 31(6), 723-751.

Stamps III, A., E. (2000). Psychology And The Aesthetics Of The Built Environment. Norwell: Kluwer Academic Publishers.

Stamps III, A., E., \& Nasar, J., L. (1997). Design review and public preferences: effects of geographical location, public consensus, sensation seeking, and architectural styles. Journal of Environmental Psychology, 17(1), 11-32. 
Taha, H., Sailor, D., \& Akbari, H. (1992). High-albedo materials for reducing building cooling energy use (pp. 1-72). Berkeley, California: University of California.

Thissen, C. (2007). Strategies for housing renovation in the Netherlands: promising technologies and cluster innovativeness. Unpublished research report of a combined internship and thesis, Utrecht University, Utrecht, the Netherlands.

van Beckhoven, E., Bolt, G., \& van Kempen, R. (2005). Theories of neighborhood change and neighborhood decline: Their significance for post-WWII large housing estates. Paper presented at the ENHR-conference "Housing in Europe: New Challenges and Innovations in Tomorrow's Cities", Reykjavik, 29 June-2 July, 2005.

van den Berkhof, F., W. (2008). Beleving van lounges op Amsterdam Airport Schiphol, vormgevingsvoorkeuren van reizigers. Unpublished Master thesis, Technische Universiteit Delft Delft.

van Eck, A., J., L., van Oel, C., J., \& Koppels, P., W. (2008). The 'willingness to pay' for newly built energy efficient houses. Paper presented at the ENHR-International Research Conference. "Shrinking Cities, Sprawling Suburbs, Changing Country sides", Dublin, 4-6 July, 2008.

Verhoef, L., G., W. (2007). Preface. In M. Andeweg, T., S. Brunoro \& L. Verhoef, G., W. (Eds.), COST C16 Improving the Quality of Existing Urban Building Envelopes State of the art (Vol. 2, pp. vii-x). Delft: IOS Press BV.

verticiel Inc. (2009). About moss tiles. Retrieved 15 October, 2009, from www.verticiel.ca

Wassenberg, F. (2004). Renewing stigmatised estates in the Netherlands: A framework for image renewal strategies. Journal of Housing and the Built Environment(19), 21.

White, E., V., \& Gatersleben, B. (2011). Greenery on residential buildings: Does it affect preferences and perceptions of beauty? Journal of Environmental Psychology, 31, 89-98.

Zijlstra, H. (2009). Analysing Buildings from Context to Detail in Time. ABCD Research Method. Amsterdam: IOS Press.

\section{ABOUT THE AUTHORS}

Dr. Francesca Riccardo: Dr. Francesca Riccardo obtained her Ph.D. in Sustainable Urban Design. She has a master degree in architectural composition. Since 2006, she deals with research and education on sustainable regeneration of residential neighborhoods with a specific focus on design strategies for buildings and open spaces. She defended her Ph.D. thesis entitled "Renovation Strategies for Social Housing Estates" on April 11, 2008 at the Roma Tre University, Italy. She did a part of her research at the Delft University of Technology, Holland, with a one year scholarship by the Rotary Foundation. In the present academic year, she is assistant professor in Principles of Environmental Impact Assessment and in Building Maintenance at the Faculty of Architecture of the Sapienza University of Rome, Italy, and since December 2010, she is researcher with a three year contract on sustainable regeneration of residential neighborhoods at the IUAV University of Venice, Italy. From 2007 to 2010, she was researcher on sustainable and aesthetic transformation of social housing at the Faculty of Architecture of the Delft University of Technology, Holland.

Clarine van Oel: Dr. Clarine J. van Oel is an environmental psychologist and assistant professor in the Department of Real Estate and Housing at Delft University of Technology, the Netherlands. Her research examines user preferences in Urban and Architectural design, particularly in housing facades, and retail design using discrete choice modeling. 
Peter de Jong: Peter de Jong is a lecturer at Building Economics, Real Estate and Housing, Faculty of Architecture, Delft University of Technology. His teaching assignment consists of cost awareness in design for architects in the Bachelor, as well as viability of projects. The research assignment is more and more focussing on defining and exploring 'sustainable building economics', in which the ideas behind this paper is forming an important element. 